Arteterapia. Papeles de arteterapia y educación para inclusión social ISSN-e 1988-8309

\title{
VI Jornada Arteterapia y educación. "CONVIVIR PARAAPRENDER" ESTRATEGIAS CREATIVAS PARA LA CONVIVENCIA EN LOS ESPACIOS EDUCATIVOS
}

María de los Llanos Alonso Borso di Carminati ${ }^{1}$

\section{SÁBADO 6 DE ABRIL 2019}

Organizada por Máster en Arteterapia UPV, y el Consorci de Museus de la Comunitat Valenciana, el sábado 6 de abril de 2019 ha tenido lugar la VI edición de la Jornada Arteterapia y educación, en el Centro de Cultura Contemporánea El Carmen.

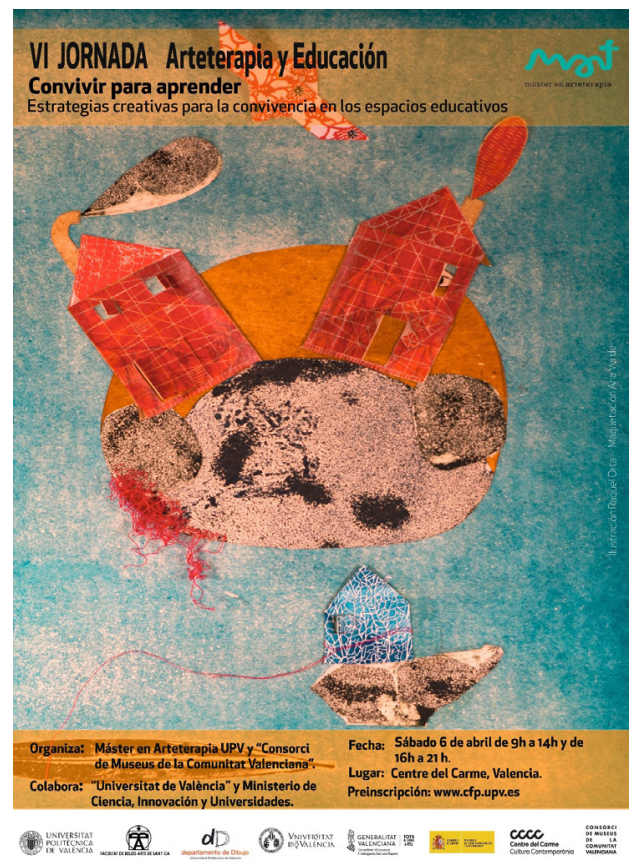

Figura 1. Cartel de las Jornadas

En esta nueva edición el tema central y eje de la reflexión fue la convivencia y los recursos creativos que, desde los diferentes lenguajes artísticos, podemos utilizar

1 Universidad Politécnica de Valencia. Departamento de Comunicación Audiovisual, Documentación e Historia del Arte, DCADHA.

E-Mail: maalbor1@har.upv.es 
para facilitar la disminución de la conflictividad en las aulas y la consciencia de las dificultades dentro del ámbito de la educación. En definitiva, fomentar la convivencia y el diálogo para mejorar los aprendizajes en el aula.

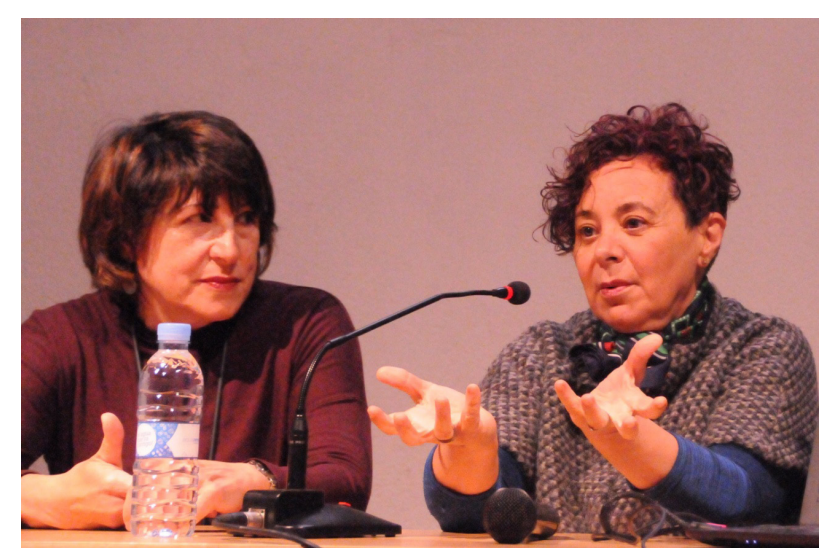

Figura 2. Ana Hernández y María Montero-Rios

Contamos en esta edición de nuevo con Lucas Platero que nos planteó a través de su conferencia "Qué es la interseccionalidad y cómo se puede poner en práctica". Rescatamos una de sus frases: "la interseccionalidad suele evocar un sujeto atravesado, una especie de cruce de caminos que trata de reflejar un interés por ir más allá de una concepción estática, homogeneizante y cuasi étnica de las desigualdades y de los colectivos". Nos hizo pensar y puso el foco sobre la discriminación múltiple. Una forma de interseccionalidad es poner en cuestión las políticas identitarias, e invita a pensar en espacios comunes, en privilegios y alianzas".

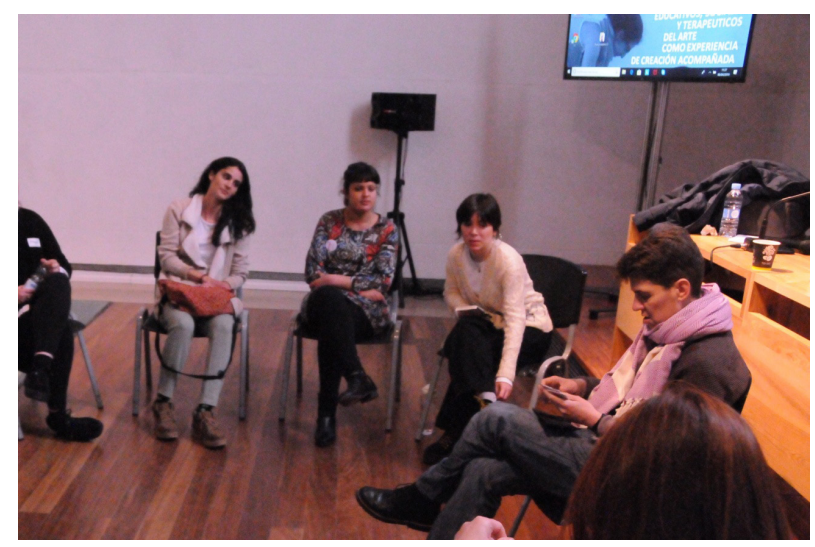

Figura 3. Taller de Lucas Platero

En los espacios de taller los y las participantes pudieron dar forma plástica y vivir la experiencia a través de distintos lenguajes artísticos, a los debates que se abrieron por la mañana. Los cuatro talleres simultáneos fueron los siguientes: 
Helena Sáez: "Contar, escuchar, acompañar imágenes para el encuentro y la no violencia". Arteterapeuta. Profesora de la Universidad de Valencia y del Master de Arteterapia de la UPV.

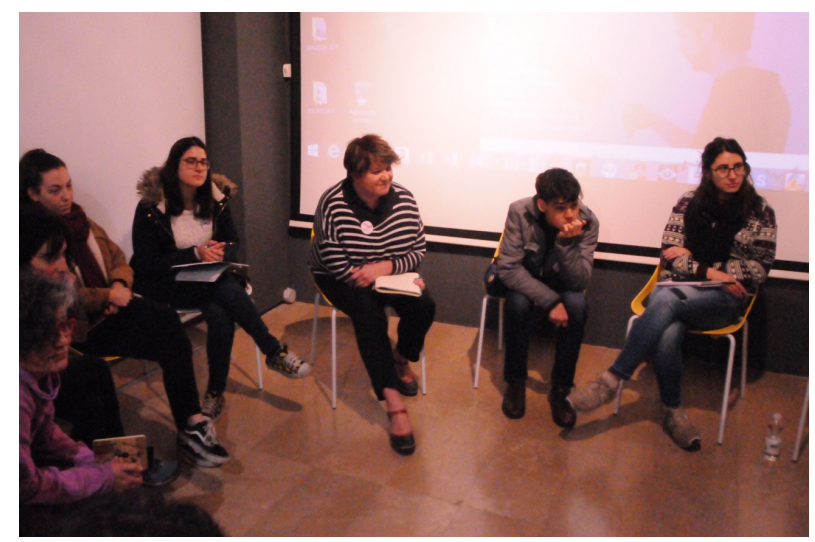

Figura 4. Taller de Helena Sáez

María Colomer: "Con humor en el aula". Psicóloga, actriz, pedagoga y payasa. Profesora del Master de Arteterapia de la UPV.

Victoria Esgueva: "Yo mí, me conmigo". Profesora de la Facultad de Bellas Artes y del Master de la UPV.

Lucas Platero: "Sexualidad e interseccionalidad ". Profesor de secundaria Madrid.

La conferencia de la tarde a cargo de Fernando Hernandez Hernandez: "Repensar las relaciones en educación desde una pedagogía de los afectos". Puso sobre la mesa preguntas: “¿Cómo imagináis unas relaciones pedagógicas atravesadas por los afectos? O ¿Qué prácticas afectivas podemos incorporar a nuestras relaciones pedagógicas? ¿Qué afectos provocan transformaciones sociales en nuestro día a día? Pone el foco en el afecto que es transversal ya que cruza todas las dimensiones del conocimiento, el sujeto como individuo y la realidad. Además, implica un cambio sustancial en política, metodología y pedagogía..." y nos quedamos también con la frase "No hablaré de lo que sé si no de lo que me afecta, de aquello que estimo.

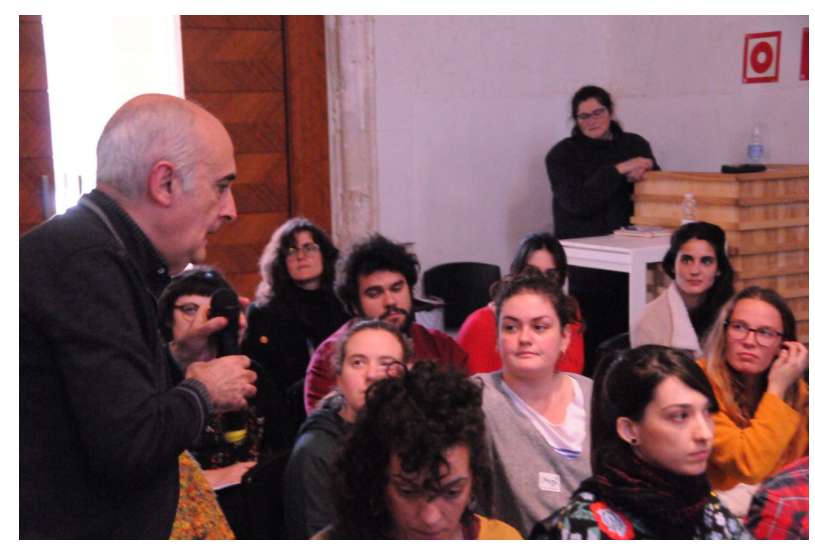

Figura 5. Conferencia de Fernando Hernandez 
Y el diálogo entre los dos conferenciantes Lucas Platero y Fernando Hernández resaltó la importancia de mejorar y potenciar los recursos en educación desde una nueva perspectiva para que de manera creativa repensemos los conceptos de identidad y los modelos de aprendizaje atravesados por el afecto.

Con el fin de dar visibilidad a los proyectos profesionales en educación, por la tarde tuvimos una mesa redonda de Comunicaciones sobre experiencias de artes y arteterapia en educación, coordinada por María Llanos Alonso. En la mesa pudimos escuchar a:

Loly Miguel Serrano: "Proyecto ZONA LIBRE Un espacio de juego creativo en la escuela Pedagogía y creatividad".

Pablo Vte Martínez y Laura Redón: "Aprendiendo de los cuentos. Taller de arteterapia para jóvenes en riesgo de exclusión".

Anna Verde y Andrea Estímoli: "Ser capaces juntos". Un proyecto de Mediación Artística en el Centro de Apoyo a la Inclusión de Asindown.

Blanca Santamaría y Mita Chueca: "Planeta de Papel. Una experiencia de arteterapia en el colegio de La Coma".

$\mathrm{M}^{\mathrm{a}}$ Dolores García: "Diálogos de papel. Propuestas metodológicas de desarrollo colaborativo basándose en el papel como vehículo de expresión plástica."

Paz Rosales: "CUENCOS, CORAZONES Y OTRAS ARMAS". Un proyecto de Grupos de Arteterapia con Preadolescentes en la Escuela (2014-2019).

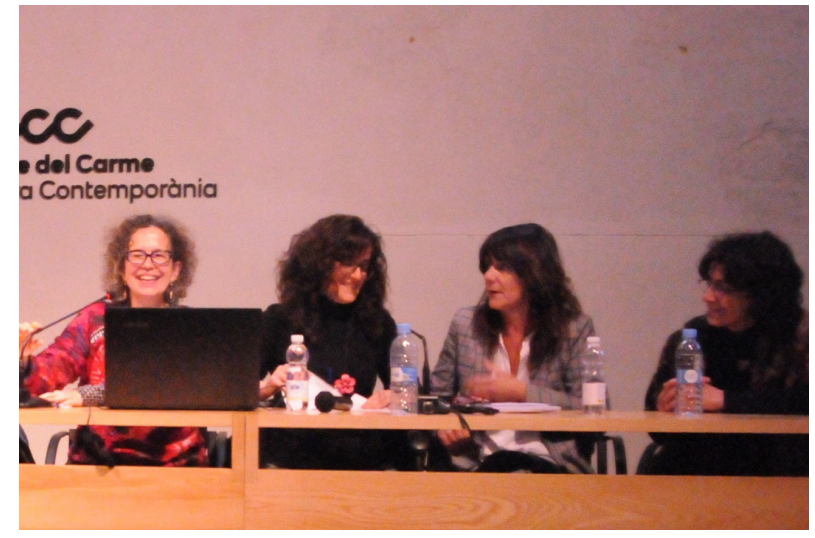

Figura 6. Mesa redonda

Y para clausurar las Jornadas pudimos disfrutar de la propuesta de Mónica Perales, directora de coros, del "Canto es un arte". Juntos pudimos experimentar que la voz es un instrumento perfecto para comunicarnos, compartir y poder hacer arte en colectividad. 